\title{
Mortality Rate in Bullous Pemphigoid: A Retrospective Monocentric Cohort Study
}

\author{
B. Cortés ${ }^{\text {a, b }} \quad$ E. Khelifa ${ }^{a} \quad$ L. Clivaz ${ }^{\text {a }} \quad$ S. Cazzaniga ${ }^{c} \quad$ J.H. Saurat ${ }^{\text {a }} \quad$ L. Naldi ${ }^{c}$ \\ L. Borradori ${ }^{b}$
}

a Service de Dermatologie, Hôpitaux Universitaires de Genève, Geneva, and b Universitätsklinik für Dermatologie, Inselspital, Bern, Switzerland; 'Centro Studi GISED, Fondazione per la Ricerca Ospedale Maggiore, Bergamo, Italy

\section{Key Words}

Bullous pemphigoid $\cdot$ Lethal outcome $\cdot$ Age $\cdot$ Dementia

\begin{abstract}
Background: Bullous pemphigoid (BP) is the most common autoimmune blistering skin disease and is associated with an increased mortality. The end points of our study were to evaluate the mortality rate in a retrospective cohort of $\mathrm{BP}$ patients followed up to 5 years after the diagnosis and to determine prognostics factors. Methods: All new cases of BP diagnosed between 1990 and 2003 in the University Hospital of Geneva were retrospectively collected. 60 patients were included, 47 (88.6\%) of whom were treated with a combination of corticosteroids and chlorambucil. Results: The 1-year, 2-year and 5-year probabilities of death were 26.7, 37.1 and $60.8 \%$, respectively. Old age, dementia and use of chlorambucil at initial doses of $6 \mathrm{mg} /$ day, but not at lower doses, were associated with poor prognosis in multivariate analysis. Conclusion: Our study confirms that BP is associated with a high mortality. The observed mortality rates are however higher than those of previous studies, which is probably related to the inclusion of more debilitated patients.

Copyright $\odot 2012$ S. Karger AG, Basel
\end{abstract}

\section{KARGER}

E-Mail karger@karger.com

www.karger.com/drm

\section{Introduction}

Bullous pemphigoid (BP) represents the most common autoimmune subepidermal blistering skin disease $[1,2]$. It is associated with an autoantibody response to the BP antigen 180 (BP180, BPAG2 or type XVII collagen) and the BP antigen 230 (BP230 or BPAG1), two components of adhesion complexes promoting dermo-epidermal cohesion [3, 4].

The clinical features of BP include generalized tense blisters with, in some cases, involvement of the mucous membranes. However, up to $20 \%$ of patients only present with mild pruritus, excoriations, eczematous, papular and/or urticarial lesions, without frank blistering [5].

In recent studies, the incidence of $\mathrm{BP}$ has been estimated to be between 7 and 42.8 new cases per million people per year [1, 2, 6-12]. A recent national prospective study has estimated the annual incidence of BP to be 12.1 new cases per million people in Switzerland [13]. BP typically affects the elderly after the age of 70 years. The risk to develop the disease in subjects older than 90 years is approximately 300 -fold higher than for those of 60 years or younger $[8,14]$.

$\mathrm{BP}$ is often a chronic disease, with spontaneous exacerbations and remissions [15]. It is associated with a 
significant morbidity and mortality rate. The first-year mortality rate varies between 10 and $44 \%$, with significant differences between Europe and the USA [12, 16, 17]. Previous studies have identified a number of negative prognostic factors, such as age, low Karnofsky performance score and use of corticosteroids $[16,18,19]$. Immunosuppressive agents, systematic use of which has not been validated, may also affect the mortality rate [20].

The aims of our study were first to assess the mortality rate of $\mathrm{BP}$ in a retrospective cohort of 60 patients managed in one Swiss referral center according to a rather homogenous protocol over 14 years and second to identify prognostic factors affecting survival.

\section{Methods}

The primary end point of this retrospective cohort study was to estimate the overall survival of BP patients with a follow-up of at least 12 months to 5 years. The secondary end point was the identification of prognostic factors affecting mortality, like age, treatments, comorbidities and immunological profile. Approval from the local ethics committee was obtained before starting the study, in line with recent recommendations of the Office for $\mathrm{Hu}$ man Research Protections.

All patients with a new diagnosis of BP admitted between 1990 and 2003 to the Dermatology Department of the University Hospital of Geneva were included in the study. Detailed follow-up information during at least 1 year after diagnosis was known for all patients. The diagnosis of BP was based on the following criteria: (1) consistent clinical features, (2) histopathological evidence of subepidermal blister formation, (3) deposits of IgG and/or C3 along the epidermal side of the basement membrane as assessed by direct immunofluorescence microscopy, and (4) presence of circulating autoantibodies binding to the epidermal side of human saline split skin or presence of IgG reactivity with BP180 and/or BP230. Alternatively, (5) if a patient's serum was not available for testing, the diagnosis was based on the presence of 3 of 4 well-established clinical criteria for BP. The latter allow the diagnosis of BP to be made with high sensitivity, specificity and positive predictive value [21]. It is noteworthy that management of the patients has been quite uniform and homogenous during the studied period. After an initial workup [22], patients have usually been treated with medium range doses of prednisone (between 0.5 and $0.75 \mathrm{mg} / \mathrm{kg}$ daily) in conjunction with chlorambucil (2$6 \mathrm{mg}$ daily) as first immunosuppressant as steroid-sparing agent. In the presence of either mild localized disease with isolated excoriated and eczematous lesions or of localized disease affecting only one body area, clobetasol propionate or other high-potency corticosteroids were prescribed as first-line agents.

Data collection forms were filled by one single investigator (L.C.) by re-examining the clinical records of all patients hospitalized during the study period. If data concerning the follow-up was missing in both the inpatient and outpatient files of the University Hospital, additional information was obtained by systematically writing and/or phoning to either the patient's physician or the patient's family. Recorded information included age at diag- nosis, results of direct and indirect immunofluorescence microscopy, presence of circulating autoantibodies, treatments introduced at diagnosis, comorbidities, date of the last interview and eventually date of death.

Continuous variables were presented as means with standard deviations (SD) and categorical variables as numbers with percentages. Cumulative survival rates along with 95\% confidence intervals (CI) at 1,2 and 5 years were calculated based on a Kaplan-Meier product-limit estimator. The log rank test was used to identify prognostic factors at 1 and 5 years in univariate analysis. Continuous variables were categorized using medians as cut-off points. Factors were also evaluated in multivariate analysis by means of Cox proportional hazard regression. Variables with $\mathrm{p}$ values $<0.15$ in the univariate analysis and selected by forward stepwise algorithm in the multivariate analysis were used for confounding adjustment. The influence of the factors on survival was expressed as hazard ratios along with $95 \%$ CI. All statistical tests were considered significant for $\mathrm{p}$ values $\leq 0.05$. All the analyses were carried out using SPSS software, version 17.0 (SPSS, Chicago, Ill., USA).

\section{Results}

In this 14 -year-long survey we identified $60 \mathrm{BP}$ patients. 34 were women (56.7\%) and 26 were men (43.3\%). The mean age at inclusion in the cohort was 79.5 years $(\mathrm{SD}=11.6)$. The age distribution ranged from 49 to 98 years. The average follow-up was 33.6 months $(\mathrm{SD}=27.5)$, ranging from 0.5 to 100.2 months. After 5 years, 26 patients (43.3\%) were lost to follow-up.

The estimated survival at 1 year was $73.3 \%(95 \% \mathrm{CI}=$ $62.1-84.5)$, at 2 years $62.9 \%(95 \% \mathrm{CI}=50.6-75.2)$ and at 5 years $39.2 \%(95 \% \mathrm{CI}=25.0-53.4)$. The median survival time after diagnosis was 39.5 months $(95 \% \mathrm{CI}=13.6-$ 65.4). The cumulative survival curve is represented in figure 1.

The secondary end point of our study was the identification of prognostic factors at 1 and 5 years.

We found no significant difference in survival between genders. However, age $\geq 80$ years was significantly associated with an increased mortality rate in our cohort $(\mathrm{p}<0.001)$. This increased risk remained in multivariate analysis, which found a hazard ratio of 5.75 (95\% CI = 2.34-14.14) at 5 years.

Among the most frequent comorbidities, we identified cardiac failure, arterial hypertension, dementia and type 2 diabetes mellitus in 31.7, 55.0, 18.3 and $10.0 \%$ of patients, respectively. Among these comorbidities, only dementia seemed an independent predictive risk factor of death in univariate analysis $(\mathrm{p}<0.001)$ at 1 and 5 years. Multivariate analysis at 5 years found a hazard ratio of 4.84 (95\% CI $=2.03-11.50)$. The other comorbidities did not have a significant impact on survival. Diabetes was 


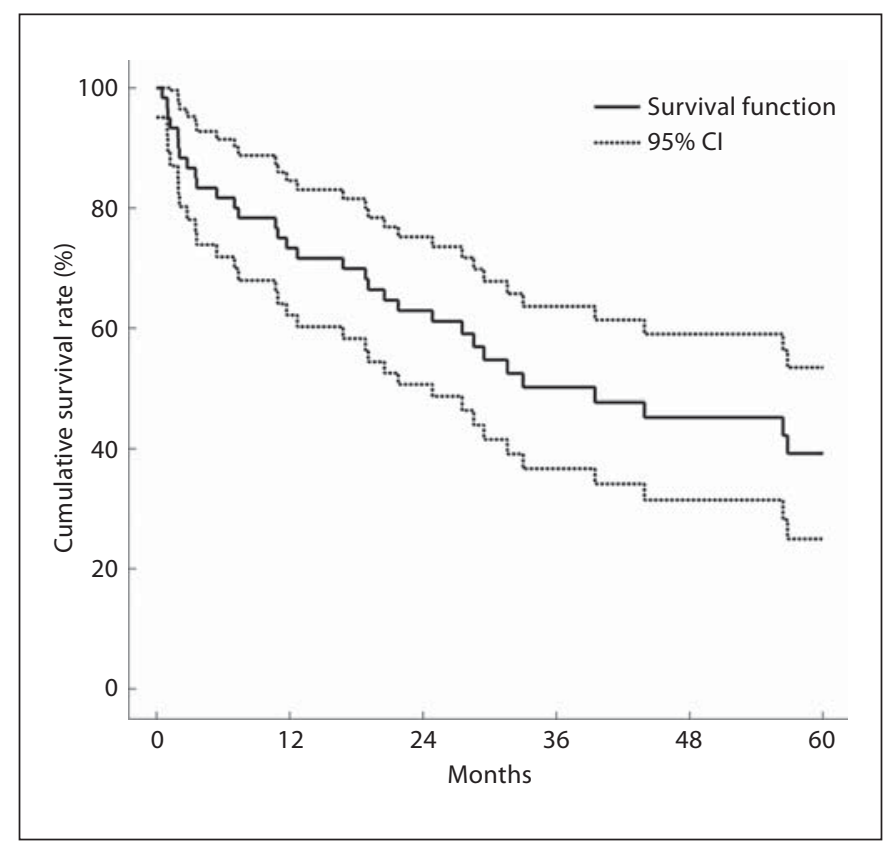

Fig. 1. Kaplan-Meier estimates of overall survival of patients with $\mathrm{BP}$ after initial diagnosis.

associated with an increased mortality rate at 1 year in univariate analyses. However, this result was not corroborated by univariate analyses at 5 years and multivariate analyses.

Since previous studies suggested that systemic steroids negatively affect survival in BP patients [23], we analyzed the impact of treatments in our cohort. 53 patients $(88.3 \%)$ were treated by oral prednisone. The average initial dose was $37.4 \mathrm{mg} /$ day $(\mathrm{SD}=17.3$ ), ranging from 10 to $120 \mathrm{mg}$. Among these 53 patients, $47(88.6 \%)$ had a combined treatment with chlorambucil. The mean dose of chlorambucil was $5.0 \mathrm{mg} /$ day $(\mathrm{SD}=1.2)$, ranging from 2 to $6 \mathrm{mg}$. The initial dose of chlorambucil was 6, 4 and $2 \mathrm{mg}$ in 46.7, 31.7 and $5.0 \%$ of these patients, respectively. The 7 patients who had not received oral prednisone were treated by topical steroids, alone or in combination. Prednisone dosage did not affect the survival of our patients. However, use of chlorambucil at an initial dose of $6 \mathrm{mg}$ daily, but not at lower doses, was associated with poor prognosis at 5 years in multivariate analysis, with a hazard ratio of 3.07 (95\% CI $=1.27-7.43$ ).

The presence of circulating autoantibodies as detected by indirect immunofluorescence microscopy, ELISA or immunoblot was not associated with an increased mortality rate [24]. Prognostic factors influencing survival at 5 years are summarized in table 1 .
Table 1. Univariate and multivariate results for lethal outcome in $\mathrm{BP}$ patients at 5 years

\begin{tabular}{|c|c|c|c|c|c|}
\hline & $\mathrm{n}$ & Univariate & analysis & Multive & iate analysis \\
\hline & & $\begin{array}{l}\text { cumulative } \\
\text { survival at } \\
5 \text { years }\end{array}$ & $\mathrm{p}$ value $\mathrm{a}^{\mathrm{a}}$ & $\begin{array}{l}\text { hazard } \\
\text { ratio }^{b}\end{array}$ & $95 \% \mathrm{CI}$ \\
\hline Gender & & & & & \\
\hline Female & 34 & $43.9 \%$ & & $1^{\mathrm{c}}$ & \\
\hline Male & 26 & $33.1 \%$ & 0.729 & 1.86 & $0.86-4.02$ \\
\hline Age & & & & & \\
\hline$<80$ years & 27 & $73.0 \%$ & $<0.001$ & $1^{\mathrm{c}}$ & \\
\hline$\geq 80$ years & 33 & $13.8 \%$ & & 5.75 & $2.34-14.14$ \\
\hline IIF & & & & & \\
\hline Negative & 9 & $53.3 \%$ & & $1^{\mathrm{c}}$ & \\
\hline Positive & 49 & $38.8 \%$ & 0.388 & 1.03 & $0.35-3.09$ \\
\hline BP180 & & & & & \\
\hline Negative & 16 & $42.9 \%$ & & $1^{\mathrm{c}}$ & \\
\hline Positive & 30 & $37.5 \%$ & 0.806 & 0.92 & $0.34-2.52$ \\
\hline BP230 & & & & & \\
\hline Negative & 24 & $44.6 \%$ & & $1^{\mathrm{c}}$ & \\
\hline Positive & 22 & $37.1 \%$ & 0.587 & 1.10 & $0.45-2.59$ \\
\hline Prednisone & & & & & \\
\hline$<40$ mg/day & 25 & $34.6 \%$ & 0.573 & $1^{\mathrm{c}}$ & \\
\hline$\geq 40 \mathrm{mg} /$ day & 28 & $43.2 \%$ & & 1.17 & $0.53-2.59$ \\
\hline Chlorambuci & & & & & \\
\hline$<6 \mathrm{mg} /$ day & 22 & $38.9 \%$ & 0.339 & $1^{\mathrm{c}}$ & \\
\hline$\geq 6$ mg/day & 28 & $32.7 \%$ & & 3.07 & $1.27-7.43$ \\
\hline Arterial hype & ertens & & & & \\
\hline No & 25 & $31.2 \%$ & & $1^{\mathrm{c}}$ & \\
\hline Yes & 33 & $47.3 \%$ & 0.599 & 0.92 & $0.44-1.93$ \\
\hline Cardiac failu & & & & & \\
\hline No & 38 & $40.5 \%$ & & $1^{\mathrm{c}}$ & \\
\hline Yes & 19 & $29.8 \%$ & 0.347 & 1.16 & $0.53-2.54$ \\
\hline Diabetes & & & & & \\
\hline No & 53 & $38.0 \%$ & & $1^{c}$ & \\
\hline Yes & 6 & $60.0 \%$ & 0.545 & 2.11 & $0.37-11.96$ \\
\hline Dementia & & & & & \\
\hline No & 48 & $45.0 \%$ & & $1^{\mathrm{c}}$ & \\
\hline Yes & 11 & $18.2 \%$ & $<0.001$ & 4.84 & $2.03-11.50$ \\
\hline $\begin{array}{r}\text { IIF = Ind } \\
{ }^{\mathrm{a}} \mathrm{p} \text { values } \\
{ }^{\mathrm{b}} \text { Estimat } \\
\text { including ter } \\
{ }^{\mathrm{c}} \text { Referen }\end{array}$ & $\begin{array}{l}\text { irect } \\
\text { of lo } \\
\text { tes fr } \\
\text { rms } f \\
\text { ce ca }\end{array}$ & $\begin{array}{l}\text { nunofluor } \\
\text { nk test. } \\
\text { Cox propo } \\
\text { ge and der } \\
\text { ry. }\end{array}$ & $\begin{array}{l}\text { escence. } \\
\text { rtional ha } \\
\text { nentia. }\end{array}$ & ard reg & sion models \\
\hline
\end{tabular}




\section{Discussion}

In extension to previous studies, our data confirm that $\mathrm{BP}$ is associated with a significant mortality rate. In our retrospective cohort of 60 patients followed over 14 years, we found the 1-, 2- and 5-year probability of death to be 26.7, 37.1 and 60.8\%, respectively. Previous European studies reported a first-year mortality rate varying between 19 and 44\% [11, 12, 16, 19, 24-26]. In our recent prospective study including all new cases of BP diagnosed between 2001 and 2002 in Switzerland [27], the 1-year, 2-year and 3-year probability of death was 20.9, 28 and $38.8 \%$, respectively. Although the $95 \% \mathrm{CI}$ of the estimated first-year mortality rate are relatively large and overlap with those of previous studies, the mean mortality rate observed in this retrospective monocentric cohort lies between the figures obtained in our prospective national study and the other European studies. The results of our retrospective study corroborate hence the idea that higher mortality rates reported in previous French studies [27] reflect a recruitment bias related to the probable inclusion of the severest and debilitated patients in referral university hospitals. In contrast, the Swiss National Study, in which lower mortality rates were reported, encompassed prospectively all newly diagnosed cases of BP, that is patients managed in both ambulatory and hospital-based settings. The lower figures observed in the latter study most likely reflect the true overall prognosis of $\mathrm{BP}$. It is noteworthy that the University Hospital of Geneva represents the only public hospital for the entire Canton of Geneva and serves as both secondary and tertiary referral center. Although all patients with BP were usually admitted for an initial screening and workup prior to starting therapy, it is likely that mild cases have been missed in our analysis. Based on an incidence of 12.1 new cases of BP per year per million inhabitants in Switzerland and a population in Geneva between 1990 and 2003 of approximately 410,000 , there should have been a total of 69.4 new cases of BP over 14 years. Based on this estimation, we have thus probably missed $15 \%$ of all $\mathrm{BP}$ cases in the Canton of Geneva. The latter are likely to correspond to the patients with mild disease and in good general condition, for whom therapy was started on an outpatient basis.

Interestingly, although a recent study including 223 patients found a 1-year mortality rate of $23 \%$ [17], two reports from the USA demonstrated a 1-year mortality rate of 10.8 and $15 \%$, respectively, whereas another study found a 2-year mortality rate of $6 \%$ [28-30]. The latter figures probably reflect differences in patients' recruit- ment between European and USA centers. In the latter, patients are rather followed in an ambulatory care setting and are likely to be in better general condition.

We also evaluated potential prognostic factors affecting mortality in our cohort. The median age of 80.5 years of the included patients was similar to that of previous studies. Advanced age, that is equal or greater than 80 years, was found to be associated with an increased mortality rate consistent with previous reports $[16,19,27]$. Sex did not affect the mortality rate in our study, in contrast to the risk associated with the female sex observed in a single previous study [25].

Presence of dementia was also associated with an increased mortality rate in our cohort. This finding is in line with previous reports in which presence of dementia as well as of other neurological diseases was found to be a poor prognostic factor [17, 27]. A recent populationbased, case-control study of Langan et al. [31] found an increased risk of stroke, dementia, Parkinson's disease and multiple sclerosis in BP patients. The risk for Alzheimer's disease also seems to be up to 3 -fold higher in BP patients than in subjects older than 75 years [32]. Another study recently found that patients with BP showed a 3.62-fold increased risk for neurological disease prior to the diagnosis of BP [33]. These observations are particularly intriguing since evidence has been provided indicating that BP180 and BP230 are expressed in the central nervous system [34-36] and mice with defects in the dystonin gene, encoding for various isoforms of BPAG1 (including the epithelial isoform BP230/BPAG1-e), develop dystonia and sensory nerve degeneration $[33,37]$.

Finally, in contrast to two previous reports, indicating that a history of cardiac diseases was associated with greater mortality, heart failure was not a poor prognostic factor in our study $[17,24]$.

One randomized multicenter prospective trial previously found that topical clobetasol propionate is effective in treating even extensive BP with a better side effect profile when compared to systemic steroids. Overall survival rates were significantly better at 1 year with potent topical corticosteroids compared to $1 \mathrm{mg} / \mathrm{kg}$ oral prednisone daily [23]. Another study suggested a correlation between the dosage of prednisone at discharge and the mortality rate [19]. In our study, prednisone dosage at start of therapy did not affect survival at 1 and at 5 years, most likely because patients were almost invariably treated with prednisone doses below $0.75 \mathrm{mg} / \mathrm{kg}$ daily, a range which appears to be better tolerated and associated with a mortality risk similar to that of potent topical steroids $[23,38]$. In contrast, we found that use of chlorambucil at an ini- 
tial dose of $6 \mathrm{mg}$ daily was a poor prognostic factor. Chlorambucil has been used in our center as first-line immunosuppressant as a steroid-sparing agent in $\mathrm{BP}$ for almost two decades, despite the lack of randomized controlled trials. However, one open prospective study reported that chlorambucil was effective in the treatment of $\mathrm{BP}$ when used in conjunction with corticosteroids. This association resulted in a decrease in both the cumulative dose of prednisone as well as the duration of therapy [39]. These findings were further confirmed in a retrospective cohort [40]. Based on the retrospective nature of the study, it is difficult to determine whether the increased mortality observed in association with initial doses of chlorambucil of $6 \mathrm{mg}$ daily is directly related to the drug itself or to other variables, such as worse general condition or presence of comorbidities in treated patients, making use of higher doses of steroids contraindicated. However, based on the present results, use of chlorambucil at initial doses of $6 \mathrm{mg}$ daily or higher should be avoided in BP. Further prospective studies are needed to better assess its usefulness in BP management.

Finally, we did not find evidence that patients with either positive ELISA BP180, ELISA BP230, indirect immu- nofluorescence or positive immunoblot studies for BP180 were associated with increased mortality. Only one previous study provided evidence suggesting that presence of autoantibodies to BP180 by immunoblotting represented a poor prognostic factor [18].

One major limitation and weakness of our study is the relatively low number of patients $(n=60)$ included in the cohort with $43.3 \%$ of the patients lost to the 5 -year followup. It is thus possible that some less evident factors associated with increased risk of death have been missed.

In conclusion, our study found a 1-year mortality rate of $26.7 \%$, which increased up to $60.8 \%$ after 5 years. Increased age and dementia were poor prognostic factors. These results thus confirm and extend previous data. Furthermore, multivariate analyses demonstrated that initial use of chlorambucil at doses of $6 \mathrm{mg}$ daily, but not at lower doses, had a negative impact on mortality rates at 5 years, although confounding variables could not be excluded.

\section{Disclosure Statement}

The authors have no conflicts of interest to declare.

\section{References}

-1 Zillikens D, Wever S, Roth A, WeidenthalerBarth B, Hashimoto T, Brocker EB: Incidence of autoimmune subepidermal blistering dermatoses in a region of central Germany. Arch Dermatol 1995;131:957-958.

-2 Bernard P, Vaillant L, Labeille B, Bedane C, Arbeille B, Denoeux JP, Lorette G, Bonnetblanc JM, Prost C: Incidence and distribution of subepidermal autoimmune bullous skin diseases in three French regions. Bullous Diseases French Study Group. Arch Dermatol 1995;131:48-52.

3 Hertl M: Humoral and cellular autoimmunity in autoimmune bullous skin disorders. Int Arch Allergy Immunol 2000;122:91-100.

-4 Stanley JR: Cell adhesion molecules as targets of autoantibodies in pemphigus and pemphigoid, bullous diseases due to defective epidermal cell adhesion. Adv Immunol 1993;53:291-325.

5 Di Zenzo G, Marazza G, Borradori L: Bullous pemphigoid: physiopathology, clinical features and management. Adv Dermatol 2007;23:257-288.

-6 Nanda A, Al-Saeid K, Al-Sabah H, Dvorak R, Alsaleh QA: Clinicoepidemiological features and course of 43 cases of bullous pemphigoid in Kuwait. Clin Exp Dermatol 2006;31:339_ 342 .
7 Serwin AB, Bokiniec E, Piascik M, Masny D, Chodynicka B: Epidemiological and clinical analysis of pemphigoid patients in northeastern Poland in 2000-2005. Med Sci Monit 2007;13:CR360-CR364.

8 Jung M, Kippes W, Messer G, Zillikens D, Rzany B: Increased risk of bullous pemphigoid in male and very old patients: a population-based study on incidence. J Am Acad Dermatol 1999;41:266-268.

$\checkmark 9$ Cozzani E, Parodi A, Rebora A, Delmonte S, Barile M, Nigro A, Priano L, Troiano G, Patri PL: Bullous pemphigoid in Liguria: a 2-year survey. J Eur Acad Dermatol Venereol 2001; 15:317-319.

10 Bertram F, Brocker EB, Zillikens D, Schmidt E: Prospective analysis of the incidence of autoimmune bullous disorders in Lower Franconia, Germany. J Dtsch Dermatol Ges 2009;7:434-440.

11 Gudi VS, White MI, Cruickshank N, Herriot R, Edwards SL, Nimmo F, Ormerod AD: Annual incidence and mortality of bullous pemphigoid in the Grampian region of north-east Scotland. Br J Dermatol 2005; 153 : 424-427.
12 Langan SM, Smeeth L, Hubbard R, Fleming KM, Smith CJ, West J: Bullous pemphigoid and pemphigus vulgaris - incidence and mortality in the UK: population based cohort study. BMJ 2008;337:a180.

13 Marazza G, Pham HC, Scharer L, Pedrazzetti PP, Hunziker T, Trueb RM, Hohl D, Itin P, Lautenschlager S, Naldi L, Borradori L: Incidence of bullous pemphigoid and pemphigus in Switzerland: a 2-year prospective study. $\mathrm{Br}$ J Dermatol 2009;161:861-868.

14 Nousari HC, Anhalt GJ: Pemphigus and bullous pemphigoid. Lancet 1999;354:667-672.

-15 Bernard P, Reguiai Z, Tancrede-Bohin E, Cordel N, Plantin P, Pauwels C, Vaillant L, Grange F, Richard-Lallemand MA, Sassolas B, Roujeau JC, Lok C, Picard-Dahan C, Chosidow O, Vitry F, Joly P: Risk factors for relapse in patients with bullous pemphigoid in clinical remission: a multicenter, prospective, cohort study. Arch Dermatol 2009;145: 537-542.

16 Joly P, Benichou J, Lok C, Hellot MF, Saiag P, Tancrede-Bohin E, Sassolas B, Labeille B, Doutre MS, Gorin I, Pauwels C, Chosidow O, Caux F, Esteve E, Dutronc Y, Sigal M, Prost C, Maillard H, Guillaume JC, Roujeau JC: Prediction of survival for patients with bullous pemphigoid: a prospective study. Arch Dermatol 2005; 141:691-698. 
17 Parker SR, Dyson S, Brisman S, Pennie M, Swerlick RA, Khan R, Manos S, Korman BD, Xia Z, Korman NJ: Mortality of bullous pemphigoid: an evaluation of 223 patients and comparison with the mortality in the general population in the United States. J Am Acad Dermatol 2008;59:582-588.

18 Bernard P, Bedane C, Bonnetblanc JM: AntiBP180 autoantibodies as a marker of poor prognosis in bullous pemphigoid: a cohort analysis of 94 elderly patients. Br J Dermatol 1997; 136:694-698.

19 Rzany B, Partscht K, Jung M, Kippes W, Mecking D, Baima B, Prudlo C, Pawelczyk B, Messmer EM, Schuhmann M, Sinkgraven R, Buchner L, Budinger L, Pfeiffer C, Sticherling M, Hertl M, Kaiser HW, Meurer M, Zillikens D, Messer G: Risk factors for lethal outcome in patients with bullous pemphigoid: low serum albumin level, high dosage of glucocorticosteroids, and old age. Arch Dermatol 2002;138:903-908.

20 Wojnarowska F, Kirtschig G, Highet AS, Venning VA, Khumalo NP: Guidelines for the management of bullous pemphigoid. $\mathrm{Br}$ Dermatol 2002;147:214-221.

21 Joly P, Courville P, Bernard P, et al: Clinical criteria for the diagnosis of bullous pemphigoid: a reevaluation according to immunoblot analysis of patient sera. Dermatology 2004;208:16-20.

22 Laffitte E, Borradori L: Management of bullous pemphigoid. Ann Dermatol Venereol 2001;128:677-680.

-23 Joly P, Roujeau JC, Benichou J, Picard C, Dreno B, Delaporte E, Vaillant L, D'Incan M, Plantin P, Bedane C, Young P, Bernard P: A comparison of oral and topical corticosteroids in patients with bullous pemphigoid. $\mathrm{N}$ Engl J Med 2002;346:321-327.
Bernard P, Enginger V, Venot J, Bedane C Bonnetblanc JM: Survival prognosis in pemphigoid. A cohort analysis of 78 patients (in French). Ann Dermatol Venereol 1995;122: 751-757.

25 Roujeau JC, Lok C, Bastuji-Garin S, Mhalla $S$, Enginger V, Bernard P: High risk of death in elderly patients with extensive bullous pemphigoid. Arch Dermatol 1998;134:465469.

26 Venning VA, Wojnarowska F: Lack of predictive factors for the clinical course of bullous pemphigoid. J Am Acad Dermatol 1992; 26:585-589.

27 Cortes B, Marraza G, Naldi L, et al: Mortality of bullous pemphigoid in Switzerland: a prospective study. Br J Dermatol 2011;165: 368-374.

28 Colbert RL, Allen DM, Eastwood D, Fairley JA: Mortality rate of bullous pemphigoid in a US medical center. J Invest Dermatol 2004; 122:1091-1095.

29 Ahmed AR, Maize JC, Provost TT: Bullous pemphigoid. Clinical and immunologic follow-up after successful therapy. Arch Dermatol 1977;113:1043-1046.

30 Fivenson DP, Breneman DL, Rosen GB, Hersh CS, Cardone S, Mutasim D: Nicotinamide and tetracycline therapy of bullous pemphigoid. Arch Dermatol 1994;130:753758.

31 Langan SM, Groves RW, West J: The relationship between neurological disease and bullous pemphigoid: a population-based case-control study. J Invest Dermatol 2011; 131:631-636.
32 Cordel N, Chosidow O, Hellot MF, Delaporte E, Lok C, Vaillant L, Bernard P, D'Incan M, Roujeau JC, Joly P: Neurological disorders in patients with bullous pemphigoid. Dermatology 2007;215:187-191.

33 Chen YJ, Wu CY, Lin MW, et al: Comorbidity profiles among patients with bullous pemphigoid: a nationwide population-based study. Br J Dermatol 2011;165:593-599.

34 Seppänen A, Suuronen T, Hofmann SC, et al: Distribution of collagen XVII in the human brain. Brain Res 2007;1158:50-56.

35 Leung CL, Zheng M, Prater SM, Liem RK The BPAG1 locus: alternative splicing produces multiple isoforms with distinct cytoskeletal linker domains, including predominant isoforms in neurons and muscles. J Cell Biol 2001;20:691-697.

36 Chen J, Li L, Chen J, et al: Sera of elderly bullous pemphigoid patients with associated neurological diseases recognize bullous pemphigoid antigens in the human brain. Gerontology 2011;57:211-216.

37 Guo L, Degenstein L, Dowling J, et al: Gene targeting of BPAG1: abnormalities in mechanical strength and cell migration in stratified epithelia and neurologic degeneration. Cell 1995;81:233-243

38 Kirtschig G, Middleton P, Bennett C, et al: Interventions for bullous pemphigoid. Cochrane Database Syst Rev 2010;6:CD002292.

39 Chave TA, Mortimer NJ, Shah DS, Hutchinson PE: Chlorambucil as a steroid-sparing agent in bullous pemphigoid. Br J Dermatol 2004;151:1107-1108.

40 Milligan A, Hutchinson PE: The use of chlorambucil in the treatment of bullous pemphigoid. J Am Acad Dermatol 1990;22:796801. 